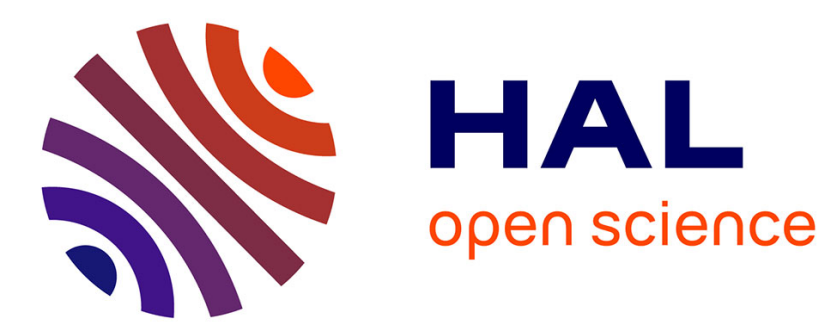

\title{
Teleconnection Pattern influence on sea wave climate in the Bay of Biscay
}

Gonéri Le Cozannet, Sophie Lecacheux, Etienne Delvallée, Nicolas

Desramaut, Carlos Oliveros, Rodrigo Pedreros

\section{To cite this version:}

Gonéri Le Cozannet, Sophie Lecacheux, Etienne Delvallée, Nicolas Desramaut, Carlos Oliveros, et al.. Teleconnection Pattern influence on sea wave climate in the Bay of Biscay. Journal of Climate, 2011, 24, p. 641-652. 10.1175/2010JCLI3589.1 . hal-00640021

\section{HAL Id: hal-00640021 https://hal-brgm.archives-ouvertes.fr/hal-00640021}

Submitted on 10 Nov 2011

HAL is a multi-disciplinary open access archive for the deposit and dissemination of scientific research documents, whether they are published or not. The documents may come from teaching and research institutions in France or abroad, or from public or private research centers.
L'archive ouverte pluridisciplinaire $\mathbf{H A L}$, est destinée au dépôt et à la diffusion de documents scientifiques de niveau recherche, publiés ou non, émanant des établissements d'enseignement et de recherche français ou étrangers, des laboratoires publics ou privés. 


\section{Teleconnection Pattern influence on sea wave climate in the Bay of Biscay}

Gonéri LE COZANNET

BRGM, Orléans, France

Sophie LECACHEUX

BRGM, Orléans, France

Etienne DELVALLEE

BRGM, Orléans, France

Nicolas DESRAMAUT

BRGM, Orléans, France

Carlos OLIVEROS

BRGM, Orléans, France

Rodrigo PEDREROS

BRGM, Orléans, France

Corresponding author address: Gonéri Le Cozannet, BRGM, Natural Risks and $\mathrm{CO}_{2}$ Storage Security Division, Coastal risks unit, BP 6009, 45060 Orléans, FRANCE

E-mail: g.lecozannet $@$ brgm.fr 


\begin{abstract}
The potential modification of hydrodynamic factors such as waves is a source of concern for many coastal communities because of its potential impact on shoreline evolution. In the northern Atlantic, swell is created by storm winds that cross the Atlantic following west-east tracks. These tracks are shifted more southward or northward depending on the season and on recurring large scale atmospheric pressure anomalies, also called teleconnection patterns. This study investigates the trends of sea wave patterns in the Bay of Biscay and relates their interannual variability to teleconnection patterns.

Sea wave parameter time series from the ERA-40 reanalysis from the ECMWF show a satisfying correlation with an in-situ buoy of Meteo-France during the time period they overlap. Using a K-Means algorithm, data from this 44-year long time series were clustered into a few sea state modes, each of them corresponding to an observable sea state associated with an averaged value for wave height, period and direction.

This analysis shows that most of the increase in annual mean sea wave height since the 1970's is due to the fact that the relative frequency of occurrence of persistent observable sea states is evolving over the time: from 1970 to 2001, the data indicate that energetic north-west swell become more frequent than low energy intermediate sea states. Moreover, anomalies of the relative frequency of occurrence of observable sea states are related to large scale recurring pressure anomalies: principally the Northern Atlantic Oscillation (NAO), but also (during winters) the East Atlantic pattern (EA), as well other teleconnection patterns of the northern hemisphere (NOAA data).
\end{abstract}

Keywords: Wave climate, wave height trends, Bay of Biscay, Teleconnection patterns, Climate variability, North Atlantic Oscillation (NAO) 


\section{Introduction}

Recently, there have been many studies presenting evidence of increasing sea wave height since the 1970's in the North Atlantic. In the context of the increasing attractiveness of coastal areas, there is growing concern that this trend will continue in the future and combine with predicted sea level rise to intensify shoreline erosion (Wang et al. 2004, Nicholls et al. 2007, Dodet et al. 2010). Coastal sea waves are one of the major factors of shoreline evolution: they are created either by local winds (wind waves) or by storm winds in the deep ocean, which then propagate to the coast (swell). Coastal wave patterns are thus a function of offshore sea state conditions, nearshore winds, and local bathymetry. Therefore, large scale North Atlantic storminess contributes to the local hydrodynamic forcing. This paper investigates the relationship between large scale and local forcing by analysing the evolution of trends of sea wave states in the Bay of Biscay and relating them to climate variability in the northern Atlantic.

The trend of increasing sea wave height in Northern Atlantic is confirmed by analysis of visual data (Gulev and Grigoreva 2004), in-situ measurements (Figure 1; Table 1; Bacon and Carter 1991), hindcast models (Kushnir et al. 1997; Wang and Swail 2001 and 2002, Dodet et al. 2010), and remote sensing altimetry (Woolf et al. 2002). The trend was related to recurrent large scale atmospheric pressure anomalies, also called teleconnection patterns. Bacon and Carter (1993) established a positive correlation between two in-situ sea wave height time series of the northern Atlantic and the North Atlantic Oscillation (NAO), which is the dominant teleconnection pattern (Wallace and Gutzler 1981). This result is consistent with the fact that the positive phase of the NAO is associated with northward-shifted storm tracks (above $50^{\circ} \mathrm{N}$ ) with a pronounced northeastern orientation and an increase in storm intensity (Rogers 1990). Moreover, Woolf et al. (2002) revealed the influence of the East Atlantic Pattern (EA) on sea wave height in the Northern Atlantic, relating the EA index to the 
position of Atlantic storm tracks: during EA+ phases, storm tracks are located at lower latitudes (between $35^{\circ} \mathrm{N}$ and $50^{\circ} \mathrm{N}$ ) and have a zonal orientation (Rogers 1990). Therefore, indices of northern Atlantic climate variability appear to be relevant features in explaining sea wave variability and trends. This is consistent with the fact that teleconnection patterns affect storminess in regions of the North Atlantic in Figure 1. The teleconnection patterns used in this paper are described in Table 2, together with the associated trends in storminess, as identified by Seierstad et al. (2007).

In the southern Bay of Biscay, however, the situation is less clear. Dupuis et al. (2006) investigated the relationship between sea wave parameters and teleconnection patterns. They analysed a 20-year time series from a waverider buoy moored at 26 meters depth off of Biscarosse in the Bay of Biscay (Figure 1, Table 1) and found a positive correlation between the NAO and the wave period, but could not relate the NAO to sea wave heights. Moreover, they could not identify a significant trend during the 20 -year period because the signal was highly instationary, the time series was relatively short, and the buoy was positioned near the coast and was likely influenced by coastal processes. More recently, Dodet et al. (2010) provided more insight on this issue by examining the spatial patterns of the correlation between the winter NAO index and single sea wave parameters in the Northeast Atlantic. They modelled waves using the NCEP/NCAR reanalysis winds and found that this index is well correlated with the peak wave period over all of the Bay of Biscay, but fits poorly with the 90th percentile sea wave height. With respect to the mean wave direction, the correlation worsens near the coast. These spatial patterns are consistent with the conclusions obtained by Dupuis et al. (2006) from the data of a single waverider buoy.

In this paper, a different approach is used to investigate how climate variability relates to local sea states in the Bay of Biscay: rather than looking for a possible influence of teleconnection patterns on a single sea wave parameter such as wave height or period, a link with the 
observable sea states is investigated. Similar to Butel et al. (2002), observable sea states are defined here as a combination of the significant wave height, mean wave period and mean wave direction. As a matter of fact, large scale atmospheric patterns influence not only the wave height but also the period and direction, and these are the three most important parameters to describe the sea wave state from a coastal morphodynamics point of view. This study tests this approach on the Bay of Biscay and investigates the following two questions: 1. Can we relate the variability of local sea wave states to large scale atmospheric conditions? 2. How can we explain the long term trend of increasing sea wave height in terms of observable sea states?

This paper will proceed as follows: in section 2 (data and methods), long term wave data and methods for analysing sea states are presented together with the teleconnection pattern data. The results of the trend analysis and the relationship found between observable sea states and various teleconnection patterns are presented in section 3 and discussed in section 4 . In section 5, the results are summarized, discussing their ability to answer the questions raised in the introduction.

\section{Data and methods}

a) wave data

This study uses the ERA-40 reanalysis of the ECMWF (Uppala et al. 2005), where the winds at $10 \mathrm{~m}$ above sea level were used to model sea wave parameters from September 1958 to August 2002 (Sterl and Caires 2004), providing 6-hour estimates of spectral significant wave height, mean wave period (T), and mean direction (D) on a global $2.5^{\circ}$ latitude $\mathrm{x} 2.5^{\circ}$ longitude grid. The significant wave height $(\mathrm{SWH})$, which is defined at the average height of the one-third largest waves, is a more common sea wave parameter than the spectral significant wave height. In deep water, these two terms can be considered as equal. In the following, it will be just referred to SWH. 
The ERA40 data point located at $45^{\circ} \mathrm{N} / 5^{\circ} \mathrm{W}$ near the Bay of Biscay was chosen for this study because of its offshore location, where it is minimally influenced by local coastal processes such as wave refraction, diffraction and bottom friction, but it is also close to the Gascogne buoy of Meteo France $\left(45.2^{\circ} \mathrm{N} / 5^{\circ} \mathrm{W}\right)$.

The ERA-40 reanalysis is not a homogeneous dataset because it progressively assimilates more and more data (e.g. remote sensing data since the 1970's). A detailed review of these inhomogeneities can be found in Caires and Sterl (2001). Nevertheless, Caires et al. (2004) validated the use of ERA-40 data for the analysis of wave climate variability with comparisons to several datasets. However, they also pointed out that using the ERA-40 dataset for the analysis of extremes is not recommended, as SWH peaks are not well modelled. Thus, this study is focused on the analysis of averaged wave modes.

Since the ERA-40 waves are generated using the ERA-40 wind forcing only (there is no assimilation of waves observations), Caires and Sterl (2003) validated this dataset against available independent datasets, namely buoy and altimeter measurements. They reported a bias in the ERA-40 significant wave height data, with an underestimation of the highest values, and they pointed out that this bias tends to increase slightly with the mean wave period. An underestimation of the monthly mean period in the Atlantic Ocean of approximately $-0.5 \mathrm{~s}$ was reported (Caires and Sterl 2001), but no validation was performed at the basin scale for the directional wave data: due to inhomogeneities in the quality of the dataset, a proper validation would require in-situ directional wave observations during the entire span of the ERA-40 data.

As an additional evaluation of the precision and accuracy of ERA-40 wave parameters, we compared the ERA40 wave parameters from the point $45^{\circ} \mathrm{N} / 5^{\circ} \mathrm{W}$ with the data of the Gascogne buoy of Meteo France $\left(45.2^{\circ} \mathrm{N} / 5^{\circ} \mathrm{W}\right)$ during the time period in which the datasets overlap, from July 1998 to August 2002. Twenty-nine outliers were excluded from the 
Gascogne buoy dataset that was then resampled at 6-hour interval to match the ERA-40 dataset (see Figures 2 and 3). The ERA-40 SWH appears to be underestimated with a bias of $0.39 \mathrm{~m}$ (Table 3 ). The linear correlation between the two datasets (see Figure 2) is very high $\left(\mathrm{R}^{2}=0.93\right)$ and significant at the 0.05 confidence level. A correction of the ERA-40 SWH values has been applied to the 1958 to 2001 ERA-40 period as defined by equation 1 :

$$
S W H_{E R A 40-C}=1.18 \cdot S W H_{E R A 40}+0.00424
$$

In the next steps of the analysis, sea wave parameters are normalized, so the effects of this correction are limited to presenting more realistic SWH in the final results. With respect to the period, the correlation is lower $\left(\mathrm{R}^{2}=0.75\right.$, significant at the 0.05 confidence level $)$, but it still shows good agreement compared to the operational models studied by Bidlot (2006). While Caires and Sterl (2001) identified an average negative bias in the North Atlantic basin for the period, the bias for the ERA $-4045^{\circ} \mathrm{N} / 5^{\circ} \mathrm{W}$ point is about $+2 \mathrm{~s}$ (Figure 3). The scatter index, which represents the dispersion of the dataset, is about $17 \%$ for both SWH and T, with a RMS error of $60 \mathrm{~cm}$ and $2.5 \mathrm{~s}$, respectively (Table 3 ). It should be noted that the resolution of the buoy dataset $(0.1 \mathrm{~m}$ for SWH and $1 \mathrm{~s}$ for the period $)$ reduces the quality of the comparison.

\section{b) Sea state clustering}

Clustering algorithms enable to obtain a synthetic picture of complex datasets, by classifying them in homogeneous classes based on defined resemblance criteria. Each class obtained by the clustering algorithm is identified by its barycentre. Data clustering classification seeks to partition the data such that each barycentre properly represents its class by minimizing the dispersion around it. Butel et al. (2002) used several unsupervised clustering algorithms for sea wave state datasets of the Bay of Biscay. We use a similar approach: the likeliness relation between two sea states is given by a normalized Euclidian scalar product in the $\{S W H, T, D\}$ space: 


$$
d\left(\begin{array}{cc}
S W H_{i} & S W H_{j} \\
T_{i} & T_{j} \\
D_{i} & D_{j}
\end{array}\right\rangle=\sqrt{\left(\frac{S W H_{i}-S W H_{j}}{\sigma_{H_{s}}}\right)^{2}+\left(\frac{T_{i}-T_{j}}{\sigma_{T}}\right)^{2}+\left(\frac{D_{i}-D_{j}}{\sigma_{D}}\right)^{2}},
$$

where $\left\{S W H_{i}, T_{i}, D_{i}\right\}$ are the significant wave height, mean period, and mean direction at timestep $i$, and $\sigma_{X}$ is the standard deviation of the subscripted parameter. The wave direction was rotated to avoid to arbitrary separate a homogeneous class possibly centred on the direction $0^{\circ}$ : as there are very few waves coming from East North East direction (around $60^{\circ}$ ), the parameter $\mathrm{D}$ was rotated of $+60^{\circ}$ before the dataset clustering. Other norms could be considered: for example, replacing $\mathrm{SWH}$ by $\mathrm{SWH}^{2}$ in formula (2) would lead to classifications of sea wave states based on wave energy density modes. Bertin et al. (2008) used this to identify a greater number of energetic wave classes. As the longshore transport is a function of $\mathrm{SWH}^{2}$ and the peak period and direction, the energetic waves classes found through this approach were relevant for analysing longshore transport. However, this paper is limited to the analysis of hydrodynamic conditions, and all three parameters are considered as equally important to classify sea wave states.

Classification algorithms use various techniques to minimize the cost function (Butel et al. 2002) with a converge nce criterion:

$$
s=\sum_{C \in P}\left(\sum_{\left\{H_{s}, T, D\right\} \in C} d\left(\begin{array}{cc}
S W H & S W H_{g} \\
T & T_{g} \\
D & D_{g}
\end{array}\right)\right)
$$

where $\left\{S W H_{g}, T_{g}, D_{g}\right\}$ identifies the barycentre of class $\mathrm{C}$ for a given partition $\mathrm{P}$ of the sea wave state dataset. The cost function is a function of the barycentres $\left\{S W H_{g}, T_{g}, D_{g}\right\}$, which has many local minima. This led Butel et al. (2002) to prefer the simulated annealing method of classifying sea wave state datasets, since this algorithm is able to escape from local optima to find a better minimum. However, our simulations show that the classical K-Means 
clustering algorithm gives similar results to simulated annealing, providing sea state estimates consistent with those of Abadie et al. (2006).

An important site-dependant parameter of these clustering algorithms is the number of predefined classes. Choosing a higher number of classes allows more accurate representation of the original dataset, but it makes the interpretation of the results more difficult. Although mathematical criteria, such as the Bayesian Information Criterium, exist to help define the number of classes to use in the analysis, it is usually defined in an empirical way, after the analysis of several trials. In the Bay of Biscay, 12 sea wave classes were used to identify the most common sea wave states as well as rarer storm sea wave states (Butel et al. 2002).

\section{c) Bivariate diagrams}

In order to provide quantitative criteria for analysing sea wave states obtained by classification, Butel et al. (2002) present bivariate diagrams that display the empirical probability density of SWH versus $\mathrm{T}$, as well as the barycentre obtained by classification. Several additional curves are added to support the analysis and distinguish wind seas, created by the local wind from swell and intermediary sea states. The so called "fully-developed" seas correspond to a theoretical limit of wind waves created by wind blowing over a long time and a large distance, so that the waves reach a theoretical equilibrium with the wind. This corresponds to a constant wave steepness $\xi$ of $1 / 19.7$ in deep water (Pierson-Moskowitz, 1964):

$$
\xi=\frac{2 \pi \cdot S W H}{g \cdot T^{2}}=\frac{1}{19.7}
$$

where $\mathrm{g}$ is the Earth's gravity. This relationship forms a parabolic curve in the $\{S W H, T\}$ space. 
Waves corresponding to swell and intermediate seas can be characterized by their age, which is obtained by solving the equation provided by Carter (1982) as a result of the Joint North Sea Wave Project (JONSWAP). In deep water, this relationship is:

$$
\frac{S W H}{T^{2}}=\lambda \cdot\left(\frac{g}{2 \pi \cdot A g e}\right)^{1 / 3},
$$

where $\lambda=0.0408 m^{-1 / 3} \cdot s^{2 / 3}$. The wave age is a nondimensional parameter.

In deep water, the total wave energy in one wavelength per unit crest width is given by the equation (USACE, 2008):

$$
E=\frac{\rho \cdot g \cdot L \cdot S W H^{2}}{8}=\frac{\rho \cdot g^{2} \cdot T^{2} \cdot S W H^{2}}{16 \cdot \pi}
$$

where $\rho$ is the sea water density and $L$ the wavelentgh. This relationship forms hyperbolic curves in the $\{S W H, T\}$ space.

Finally, once these curves are drawn in the bivariate diagram, the waves classes found by unsupervised clustering can be grouped using the following criterion:

- Waves lying between the Pierson-Moskowitz curve (Steepness=1/19.7) limit and the curve Age $=0.8$ can be considered as wind seas

- The most aged waves are usually considered as swell. Typically, Butel et al. (2002) consider that waves lying bellow the constant age curve that separates the wave dataset in two equal parts can be considered as swell.

- Other waves lying between the curve Age $=0.8$ and the swell limit used for the previous criteria can be considered as intermediate waves between swell and wind sea (Aarnes and Krogstad, 2001).

- Curves showing iso-energy fluxes also enable to identify more energetic wave conditions associated to storms as well as low energy waves. 
- Finally, waves showing similar direction or occurring during the same season can also be grouped together.

Using these criteria allows to better identify the nature of each wave class and to eventually group them upon these similarity criteria.

\section{d) Teleconnection patterns}

Time series of teleconnection patterns are obtained from the NOAA Climate Prediction Center. The teleconnection patterns used here are those described by Barnston and Livezey (1987) and are obtained by applying an orthogonal rotated principal component analysis of monthly $700 \mathrm{mb}$ heights means over the northern hemisphere.

\section{Results}

\section{a) Wave climate in the Bay of Biscay}

The 1958-2001 corrected sea wave data from ERA-40 were classified into 12 modes using the K-means algorithm (Table 4) and plotted in the bivariate diagram (Figure 4). Each identified class is described by its barycentre. The seasonality of these wave classes, shown in Figure 5, reveals more energetic winter waves and lower energy summer waves. The criteria provided in $\S 2 \mathrm{c}$ provide an objective framework based on wave age and energy flux to distinguish these classes using the bivariate diagram (Figure 4). This enables the grouping of the 12 classes into three wave types: swell, wind sea waves, and intermediate sea states.

As stated in $\S 2 \mathrm{c}$, the duplets lying between the curve Age $=0.8$ and Steepness $=1 / 19.7$ in Figure 4 can be considered as wind seas. Since class A is lying on the curve Age $=0.8$, and an eastern wind is associated with this class, class A can be considered as wind waves associated with winds coming from the continent.

The most aged waves (over Age=6.56) are swell (classes G, H, I, J). They can be divided into low energy summer swell (classes $\mathrm{G}$ and $\mathrm{H}$ ) and high energy winter swell (classes I and J), 
hereafter called SWELL 1 and SWELL 2, respectively. SWELL 1 are characterized by relatively low wave heights, long periods and a north-west direction. They occur predominantly during the summer season and occur during $32 \%$ of the ERA-40 reanalysis period. SWELL 2 are characterized by large wave heights, long periods, and north-west directions. They are more frequent in winter and occur during $17 \%$ of the ERA-40 reanalysis period.

Classes between the ages of 0.8 and 6.56 represent intermediate sea states between swell and wind sea waves (Classes B, C, D, F, E, K and L). In this range of wave heights, these wave classes are characterized by low periods. They can be divided into two groups: (1) low energy intermediate sea states hereafter called INTER 1 that are more frequent in summer (classes B, $\mathrm{C}$ and D); (2) moderate energy intermediate sea states (INTER 2) that are more frequent in winter (Classes E and F); and (3) high energy intermediate sea states (STORM) that correspond mainly to winter storms (Classes $\mathrm{K}$ and L). Classes F, K, and L actually include some wind sea waves. Nevertheless, because of their direction and of their barycentre being located bellow the Age $=0.8$ curve, they include more intermediate sea states than wind seas and are considered as such. All of these waves originate from the north-west, except class B, which comes from the north. Those waves are created by relatively gentle north-west winds, but their development is limited by a geographical constraint: as the British Isles are located north of the ERA-40 point, the fetch cannot be sufficiently large to generate more developed sea states.

The seasonality and wave flux energy criteria are used to consider a group formed by STORM and SWELL 2 waves, which correspond to the most energetic waves and will be referred to as SWELL 2 + STORM hereafter. Low and moderate energy intermediate waves (INTER 1 and INTER 2) will be referred to as INTER hereafter.

\section{b) SWH trend}


This paragraph investigates how the trend of increasing wave height in the northeastern Atlantic since 1970 can be explained using the above classification. From 1958 to 1970, no sign ificant trend appears in the ERA40 SWH signal at the $45^{\circ} \mathrm{N} / 5^{\circ} \mathrm{W}$ node. Between 1970 and 2001, however, an increase of $0.8 \mathrm{~cm} /$ year is calculated in the annual mean SWH (Table 5), with a probability higher than $99.3 \%$ for this trend to be significant. According to the ERA-40 model, the trend leads to an increase of about $25 \mathrm{~cm}$ in $\mathrm{SWH}$ at the $45^{\circ} \mathrm{N} / 5^{\circ} \mathrm{W}$ node for the last 31 years of the re-analysis.

Three different assumptions can be made to interpret this trend in terms of observable sea states: the increase in sea wave height could correspond to (1) an increase of the average SWH of all or certain wave groups, (2) a different relative frequency of occurrence of already existing wave groups, or (3) the emergence of new wave class.

Using geomorphological indicators of the French Atlantic coast, Hénaff (2008) suggests that 1985 was the transition from a more zonal to a more meridional sea wave orientation. Hypothesis (3) was tested by classifying ERA40 sea wave time series over two different periods from 1958 to 1984 and from 1985 to 2001 to identify the appearance of new classes. The results of clustering over these two different periods revealed similar barycentres, thus refuting the hypothesis of the emergence of new sea state classes after 1985.

The relative importance of assumptions (1) and (2) can be estimated approximately as follows: mean sea wave height over a given period of time can be calculated by adding the weighted means of SWH over this period of time, for each set $\mathrm{C}$ of the partition $\mathrm{P}$ of sea wave states found after the K-Means clustering. Therefore, $\overline{S W H}$ being the mean SWH for the 40 years of the ERA-40 reanalysis, $S W H_{X}$ being the mean of the significant wave height for the set $\mathrm{X}$ and $p_{X}$ being the relative frequency of occurrence of the set $\mathrm{X}$, leads to the following equation: 


$$
S W H-\overline{S W H}=\sum_{X \in P} p_{X} \cdot\left(S W H_{X}-\overline{S W H}\right)
$$

which provides an approximation for small variations of SWH over a given period of time:

$$
\Delta S W H=\sum_{X \in P} p_{X} \cdot \Delta S W H_{X}+\Delta p_{X} \cdot\left(S W H_{X}-\overline{S W H}\right)
$$

In this equation, the variations due to SWH changes within a given class $\mathrm{X}$ and those due to the relative frequency of occurrence changes $p_{X}$ are isolated. In practice, the relative importance of the $p_{X} \times \Delta S W H_{X}$ terms dominate over the relative importance of $\Delta p_{X} \times S W H_{X}$ terms, accounting for about $75 \%$ of SWH increase. The three major contributions in equation (8) are from $p_{\text {SWELL2 }} \times \Delta S W H_{\text {SWELL2 }}, p_{\text {INTER1 }} \times \Delta S W H_{\text {INTER1 }}$, and $\Delta p_{\text {INTER1 }} \times\left(S W H_{\text {INTER1 }}-\overline{S W H}\right)$, accounting respectively for approximately $40 \%, 25 \%$ and $15 \%$ of SWH increase. These trends correspond to the significant trends in Table 5. Therefore, the identified sea state classes remain persistent in time, and the evolution of relative frequency of occurrence of these groups accounts for most of the SWH trend between 1970 to 2001.

\section{c) Links between teleconnection patterns and sea wave states: annual means}

While the annual mean relative frequency of occurrence of SWELL 1 waves remains relatively stable during the ERA-40 period, the relative frequency of occurrence of the most energetic waves (SWELL $2+$ STORM) show important interannual variability. SWELL $2+$ STORM relative frequency of occurrence anomalies (compared to the mean over the ERA-40 simulation period) and the NAO index have been plotted together in Figure 6. A positive anomaly of the SWELL $2+$ STORM relative frequency of occurrence is generally observed during $\mathrm{NAO}+$ years, which indicates a relationship between this large-scale persistent atmospheric anomaly and local sea waves in the Bay of Biscay. This is confirmed by the correlation coefficient between the annual (civil year) NAO index and the annual relative frequency of occurrence of SWELL $2+\operatorname{STORM}(\mathrm{R}=0.63$; see Table 6), which is significant at the 0.05 confidence level. 
On the opposite, there are more waves of WIND SEA and INTER during NAO- years. The correlation coefficient between the NAO index and the annual relative frequency of occurrence of WIND SEA and INTER are -0.31 and -0.46 , respectively (both significant at the 0.05 confidence level; see Table 6 ).

Finally, the annual relative frequency of occurrence of SWELL 1 and INTER 1 remain more stationary than the other wave types over the ERA-40 reanalysis period (Table 7).

Using the annual mean relative frequency of occurrence of waves types, no evidence of the influence of other teleconnection patterns on sea wave climate in the Bay of Biscay could be found, with the exception of EA, which is correlated with INTER 1 relative frequency of occurrence and of EP/NP (a northern pacific pattern), which is correlated with SWELL $2+$ STORM. These results are discussed in $\S 4$.

\section{d) Links between teleconnection patterns and sea wave states: winter means}

During winter months, SWELL 1 waves become less frequent so that SWELL 2 and STORM wave groups become dominant (Figure 5). Thus, during this season, the sensitivity of waves to teleconnection pattern variability is expected to be most apparent.

As a matter of fact, the correlation between the NAO index and the SWELL $2+$ STORM relative frequency of occurrence during winter is significant at the 0.05 confidence level $(\mathrm{R}=0.58)$, and in addition, the East Atlantic pattern also is correlated with STORM + SWELL 2 relative frequency of occurrence anomaly during the winter $(R=0.56$; significant at the 0.05 confidence level) (Table 7). If the period of interest is restricted to single months during the winter, the correlations show that the relative influence of the NAO, EA, and EA/WR varies from one month to another: while in January, February and March, the NAO accounts for most of the variance of the SWELL $2+$ STORM relative frequency of occurrence variability behaviours, the EA explains most of this variance in December $(\mathrm{R}=0.56)$. As an attempt to explain this, one can notice that EA explains $11 \%$ of the variance of mean $700 \mathrm{mb}$ height in 
December, while this value is below $9.5 \%$ for all other months and is even below $5 \%$ when February is excluded (Barnston and Livezey, 1987). Thus, this teleconnection pattern is expressed mostly in December so that during this month, a larger manifestation of EA would be expected.

\section{Discussion}

\section{a) Use of clustering algorithm}

Instead of analysing a single sea wave parameter, we used a clustering algorithm to consider three wave parameters (significant height, period and direction) equally to finally enable the identification of observable sea states and attempt to explain previously observed trends. From a methodological point of view, this technique provides a practical framework to describe long time series of wave parameters with only several dominant modes.

An important issue is the sensitivity of the final results to the classification. A key parameter

to define is the number of classes defined by the user prior to applying the K-Means algorithm. As stated above (see $\S 2 \mathrm{~b}$ ), there is a trade-off between (1) few classes, potentially causing oversimplification and poor representation of the observed sea wave signal, and (2) many classes, ignoring the initial objective of simplifying the signal. Using their knowledge of the hydrodynamic conditions in the Bay of Biscay, Butel et al. (2002) showed that 12 classes was an appropriate trade off, but this value is site-dependant and would need to be reconsidered in other seas of the world.

Once the number of classes is chosen, bivariate diagrams can be used to qualify each class and group them. Here, quantitative criteria can be used: mean direction of each class, PiersonMoskowitz (1964), wave iso-age curves such as in Butel et al. (2002), and also energy fluxes (see $\S 2 \mathrm{c}$ and $\S 3 \mathrm{a}$ ). Our experience from the number of tests performed within this study is that the sensitivity of the final results to the classification and grouping mainly lies in the choice of an appropriate number of classes. In other terms, once the classes correspond to the 
main observable sea states, an extensive analysis of the links between teleconnection patterns and those sea wave states can be performed.

\section{b) Links between teleconnection patterns and sea wave states: annual means}

Our results confirm that large scale atmospheric anomalies partly control the sea wave climates in the Bay of Biscay. With respect to the annual means, the correlations found in Table 6 show that a more intense positive NAO index generally leads to higher relative frequency of occurrence of SWELL 2 and STORM and a smaller frequency of occurrence of INTER, particularly INTER 2 . This can be related to typical storm tracks associated to NAO+ and NAO-: NAO+ is associated with stronger, northward-shifted winds over the northern Atlantic, while NAO- is associated with weaker southward-shifted winds. This agrees with the interpretation of Dupuis et al. (2006): as storm tracks shift northward to the GreenlandIcelandic region during $\mathrm{NAO}+$, the waves travel a longer distance to reach the Bay of Biscay. Consequently, when these waves propagate to the Bay of Biscay, their height is attenuated and their wavelength increases because of the dispersive character of sea wave propagation. The fact that the largest waves and longest periods are associated with positive phases of $\mathrm{NAO}$ is thus consistent with an intuitive analysis.

Other correlations can be also related to intuitive analysis: winds coming from the continent will typically occur when the NAO index is negative, explaining the significant correlation observed between WIND SEA relative frequency of occurrence and NAO-.

With respect to the significant correlation between EP/NP and SWELL $2+$ STORM relative frequency of occurrence, this result might seem surprising, but it is consistent with the results of Seierstad et al. (2007) who found an increase of one standard deviation of the EP/NP index to be associated with a statistically significant increase of storminess in the Bay of Biscay.

As INTER 1 does not correspond to stormy winds, this kind of wave was not a point of focus in previous studies. However, Table 6 shows that the correlation of the INTER 1 relative 
frequency of occurrence with EA is significant. This seems to correspond to the case where a positive EA index is associated with relatively weak western winds creating waves over the eastern Atlantic, which causes intermediate seas in the bay of Biscay.

Having mentioned those two specific cases, Table 6 confirms that when considering annual means, the NAO remains the most relevant teleconnection pattern to consider when relating the Bay of Biscay's sea wave states to teleconnection patterns.

\section{c) Links between teleconnection patterns and sea wave states: winter means}

Table 7 confirms the links between local wave climate and NAO in winter, but also the influence of other teleconnection patterns on sea can be highlighted: in Table 7, the correlation between EA and STORM can be related to the results of Seierstad et al. (2007), who showed that EA+ phases are associated with storms affecting the east central part of northern Atlantic region (Figure 1). The wave group STORM is thus related to typical EA+ storms, which are created closer to the Bay of Biscay. They are thus characterised by larger wave heights and shorter periods, which explains their proximity to the wind sea theoretical limit (Age=0.8) in Figure 4.

Similarly, positive phases of the EA/WR pattern also lead to more SWELL 2 waves and less STORM waves: this is consistent with the fact that positive phases of this pattern are associated with fewer storms in the Bay of Biscay according to Seierstad et al. (2007).

Nevertheless, it must be noted that non intuitive relationships between sea wave state and teleconnection patterns can also be reported. Another relation between the West Pacific pattern and positive anomalies of the SWELL 2 relative frequency of occurrence during winter remains unexplained as Seierstad et al. (2007) did not report significant storm changes in northern Atlantic for positive phases of the WP (Table 2).

This focus on winter sea wave state variability confirms the influence of teleconnection patterns other than the NAO. Most of this influence corresponds to basic intuitive relations 
between teleconnection patterns, storminess and sea states, with the notable exception of the WP. In this context, sea wave height trends relate to climate variability in northern Atlantic: particularly, the increase of SWH from 1970 to 2001 can be related with recurring yearly means $\mathrm{NAO}+$ anomalies.

\section{Conclusion}

One major motivation to study sea wave variability is its possible consequences in terms of erosion of the shoreline. West in the Bay of Biscay, the 240km-long Aquitaine sandy coast is exposed to energetic and slightly shore-oblique waves that account for longshore currents and drift (Komar and Inman 1970). Castelle et al. (2007) extensively described the very active morphodynamic processes of this environment, showing waves as an important forcing agent. Dodet et al. (2010) even suggested that changing wave patterns could be an additional explanation for increased erosion over the last 50 years in Western Europe. In this context, this study focused on the two questions set out in the introduction:

1. Can we relate the variability of local sea wave states to large scale atmospheric conditions? A link exists between the annual relative frequency of occurrence of wave types in the Bay of Biscay and interannual variability of the NAO. During NAO+ periods, stronger winds cross the northern Atlantic and create larger waves, here classified as SWELL $2+$ STORM. NAOis characterized by weaker winds and more southern oriented winds over the north Atlantic. The Bay of Biscay is then under the influence of WIND SEA or INTER waves. The correlation is even more obvious during the winter season. The summer season is mostly characterised by SWELL 1 waves that are not affected by NAO variability. The influence of other teleconnection patterns on North Atlantic storminess is also confirmed: EP/NP annually and EA, EA/WR, and, surprisingly WP in winter.

2. How can we explain the long term trend of increasing sea wave heights in terms of observable sea states? 
The long term increasing trend since 1970 can be explained mostly by an increase of the relative frequency of occurrence of the most energetic swell group (SWELL 2), then, to a lesser extent, by a decrease of the relative frequency of occurrence of low energy intermediate waves (INTER 1) and finally by an increase of mean sea wave heights for this same group. From a methodological point of view, this study shows the relevance of using sea wave clustering to relate observable sea states to large scale climate variability indices. This approach makes the correlation between the teleconnection patterns and sea wave climates easier to interpret. Key prerequisites are the existence of a sufficiently long sea wave data time series, including height, period and direction, and the existence of in-situ observations to validate the data if it originates from a model.

\section{Acknowledgments.}

The ERA-40 sea wave reanalysis from ECMWF, and teleconnection patterns from the historical archive of NOAA were used for this study, which has been supported by the BRGM Research Directorate under the Riscot project and the French National Research Agency through the VULSACO project (ANR-06-VULN-009). Support of the European Commission for trends and bivariate analysis is gratefully acknowledged through FP7 MICORE (Contract 202798) and THESEUS (Contract 244104) projects respectively. We thank Dr. M. YatesMichelin, Dr. D. Idier and anonymous reviewers for their comments that led to improving this manuscript. 


\section{References}

Aarnes, J.E., H.E. Krogstad, 2001: Partitioning sequences for the dissection of directional ocean wave spectra: A review. Part of work package 4 (Wp4) of the EnviWave (EVG-200100017) research programme under the EU Energy, Environment and Sustainable Development programme. [Available online at: http://www.oceanor.no/projects/enviwave/PartitioningSequences.pdf]

Abadie, R. Butel, S. Mauriet, D. Morichon, H. Dupuis, 2006: Wave climate and longshore drift on the South Aquitaine coast. Cont. Shelf Res., 26, 1924-1939.

Bacon, S. and D.J.T Carter, 1991: Wave climate changes in the north Atlantic and North Sea. International Journal of Climatology, 11, 545-558.

Bacon, S. and D.J.T Carter, 1993: A connection between mean wave height and atmospheric pressure gradient in the North Atlantic. International Journal of Climatology, 13, 423-436.

Barnston, A. G., and R. E. Livezey, 1987: Classification, seasonality and persistence of lowfrequency atmospheric circulation patterns. Mon. Wea. Rev., 115, 1083-1126.

Bertin X., B. Castelle, E. Chaumillon, R. Butel, R. Quique, 2008 : Longshore transport estimation and inter-annual variability at a high-energy dissipative beach: St. Trojan beach, SW Oléron Island, France. Cont. Shelf Res., 28, 1316-1332

Bidlot J-R., D. Holmes, P. Wittmann, R. Lalbeharry, H. Chen, 2001: Intercomparison of the performance of operational ocean wave forecasting systems with buoy data. Wea. Forcasting, $17,287-310$

Bidlot J.-R. and M.W. Holt, 2006: Verification of operational global and regional wave forecasting systems against measurements from moored buoys. JCOMM Technical Report, 30. WMO/TD No.1333. [Available online at: ftp:/ftp.wmo.int/Documents/PublicWeb/amp/mmop/documents/JCOMM-TR/J-TR-30/J-TR30.pdf] 
Butel, R., H. Dupuis, and P. Bonneton, 2002: Spatial variability of wave conditions on the French Atlantic coast using in-situ data. Journal of Coastal Research, 36, 96-108.

Caires, S., and A. Sterl, 2003: Validation of ocean wind and wave data using triple correlation. J. Geophys. Res., 108, 3098.

Caires, S., A. Sterl, J.-R. Bidlot, N. Graham, and V. Swail, 2004: Intercomparison of different wind-wave reanalyses. J. Climate, 17, 1893-1912.

Caires, S. and A.Sterl, 2001: Comparative assessment of ERA-40 ocean wave product. Proc. Of the ECMWF workshop on re-analysis, ERA-40 Project Report Series, 3, 353-368, Reading, 5-9 November 2001. [Available online at: http://www.knmi.nl/home/onderzk/oceano/waves/era40/reports/knmi1101.pdf] Carter, D. J. T., 1982: Prediction of wave height and period for a constant wind velocity using the JONSWAP results. Ocean Eng., 9, 17-33.

Castelle, B., P. Bonneton, H. Dupuis, N. Sénéchal, 2007: Double bar beach dynamics on the high-energy meso-macrotidal French Aquitanian Coast: A review. Marine Geology, 245, 141-159.

Dodet, G., X. Bertin, R. Taborda, 2010: Wave climate variability in the North-East Atlantic Ocean over the last six decades. Ocean Modelling, 31, 120-131.

Dupuis, H., D. Michel, and A. Sottolichio, 2006: Wave climate evolution in the Bay of Biscay over two decates. J. Mar. Syst, 63, 105-114.

Gulev, S.K., and V. Grigorieva, 2004: Last century changes in ocean wind wave height from global visual wave data. Geophys. Res. Lett., 31, L24302, doi:10.1029/2004GL021040.

Hénaff, A., 2008 : Identification of geomorphological indicators of incident waves direction along the Channel and the Atlantic French coasts during the last 25 years, data analysis and comparison with data of the EDF-LNHE numerical atlas of waves, (in French), la Houille Blanche, 1, p. 61-71. 
Komar P.D., and D.L. Inman, 1970: Longshore sand transport on beaches. J. Geophys. Res, 75, 5914-5927.

Kushnir, Y., V. J. Cardone, J. G. Greenwood, and M. A. Cane, 1997: The recent increase in North Atlantic Wave Heights. J. Climate, 10, 2107-2113.

Nicholls, R.J., P.P. Wong, V.R. Burkett, J.O. Codignotto, J.E. Hay, R.F. McLean, S.

Ragoonaden and C.D. Woodroffe, 2007: Coastal systems and low-lying areas. Climate Change 2007: Impacts, Adaptation and Vulnerability. Contribution of Working Group II to the Fourth Assessment Report of the Intergovernmental Panel on Climate Change, M.L. Parry, O.F. Canziani, J.P. Palutikof, P.J. van der Linden and C.E. Hanson, Eds., Cambridge University Press, Cambridge, UK, 315-356.

Pierson, W. J. and L. Moskowitz, 1964: A proposed spectral form for fully developed wind seas based on the similarity theory of A. A. Kitaigorodskii. J. Geophys. Res., 69, 5181-5190. Rogers, J.C., 1990: Patterns of low frequency monthly sea level pressure variability (18991986) and associated wave cyclone frequencies. J. Climate, 3, 1364-1379.

Seierstad, I. A., D. B. Stephenson, N. G. Kvamstø, 2007, How usefull are teleconnection patterns for explaining variability in extra-tropical storminess? Tellus Series A-Dynamic Meteorology and Oceanography, 59(2), 170-181.

Sterl, A., and S. Caires, 2004: Climatology, Variability and Extrema of Ocean Waves - The Web-based KNMI/ERA-40 Wave Atlas. International Journal of Climatology, 25, 963-997. Wang X.L., and V.R. Swail, 2001: Changes of extreme wave heights in northern hemisphere oceans and related atmospheric circulation regimes. J. Climate, 14, 2204-2221.

Wang X.L.2 and V.R. Swail, 2002: Trends of Atlantic wave extremes as simulated in a 40year wave hindcast using kinematically reanalysed wind fields. J. Climate, 15, 1020-1035. Wang X.L., F.W. Zwiers and V.R. Swail, 2004: North Atlantic ocean wave climate change scenarios for the twenty-first century. J. Climate, 17, 2368- 2383. 
Wallace JM, Gutzler DS. 1981. Teleconnections in the geopotential height field during the Northern Hemisphere winter. Mon. Wea. Rev. 109: 784-812.

Woolf, D.K., P.D. Cotton, and P.G. Challenor, 2002: Variability and predictability of the North Atlantic wave climate. J. Geophys. Res., 107, 3145.

USACE, 2008: U.S. Army Corps of Engineers Coastal Engineering Manual - Part II -

Chapter 1 - Water wave mechanics, [available online at:

http://140.194.76.129/publications/eng-manuals/em1110-2-1100/PartII/PartII.htm]

Uppala, S.M., Kållberg, P.W., Simmons, A.J., Andrae, U., da Costa Bechtold, V., Fiorino, M., Gibson, J.K., Haseler, J., Hernandez, A., Kelly, G.A., Li, X., Onogi, K., Saarinen, S., Sokka, N., Allan, R.P., Andersson, E., Arpe, K., Balmaseda, M.A., Beljaars, A.C.M., van de Berg, L., Bidlot, J., Bormann, N., Caires, S., Chevallier, F., Dethof, A., Dragosavac, M., Fisher, M., Fuentes, M., Hagemann, S., Hólm, E., Hoskins, B.J., Isaksen, L., Janssen, P.A.E.M., Jenne, R., McNally, A.P., Mahfouf, J.-F., Morcrette, J.-J., Rayner, N.A., Saunders, R.W., Simon, P., Sterl, A., Trenberth, K.E., Untch, A., Vasiljevic, D., Viterbo, P., and Woollen, J. 2005: The ERA-40 re-analysis. Quart. J. R. Meteorol. Soc., 131, 2961-3012. 
$25 / 33$ 


\section{List of figures captions}

Figure 1. Map of the North Atlantic indicating the location of sea wave data (see Table 1) and wave generation regions (see Table 2) considered in this study.

Figure 2. A regression curve of ERA-40 modelled SWH versus the Gascogne buoy observations during the overlapping time period from July 1998 to August 2002. Gray scaling indicates the dataset density.

Figure 3. Comparison of SWH and T modelled in ERA-40 versus the Gascogne buoy observations over a subset of the overlapping period from January 2000 to January 2001.

Figure 4: Bivariate diagram plotting T against SWH. Contour lines are plotted around 100\%, $85 \%, 51 \%, 26 \%$ and $8 \%$ of the dataset. Barycentres obtained by classification are designated according to Table 4 together with their mean direction. The curve of constant steepness 1/19.7 corresponds to fully developed seas. Waves located above the curve of a constant age of 0.8 correspond to wind seas. The curve corresponding to a constant age of 6.56 corresponds to the mean ( $50 \%$ of the waves are lying below this curve). The iso-energy fluxes are also plotted for the $50^{\text {th }}, 75^{\text {th }}$ and $90^{\text {th }}$ percentiles, corresponding respectively to values of $620 \mathrm{~kJ} / \mathrm{m}, 1.6 \mathrm{MJ} / \mathrm{m}, 4.2 \mathrm{MJ} / \mathrm{m}$.

Figure 5. Seasonal occurrence of the 12 classes for the period 1958-2001

Figure 6. Time series of mean annual NAO index (histogram) compared to annual occurrence anomalies of SWELL $2+$ STORM waves (thin bars) 


\section{Figures}

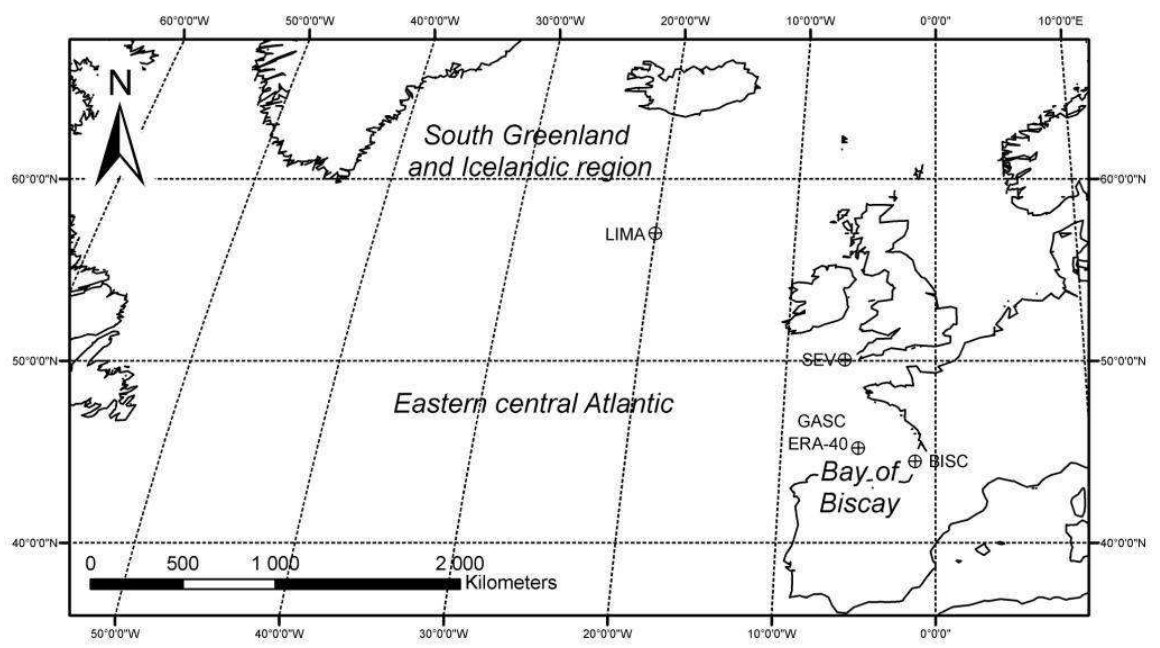

Figure 1. Map of the North Atlantic indicating the location of sea wave data (see Table 1) and wave generation regions (see Table 2) considered in this study.

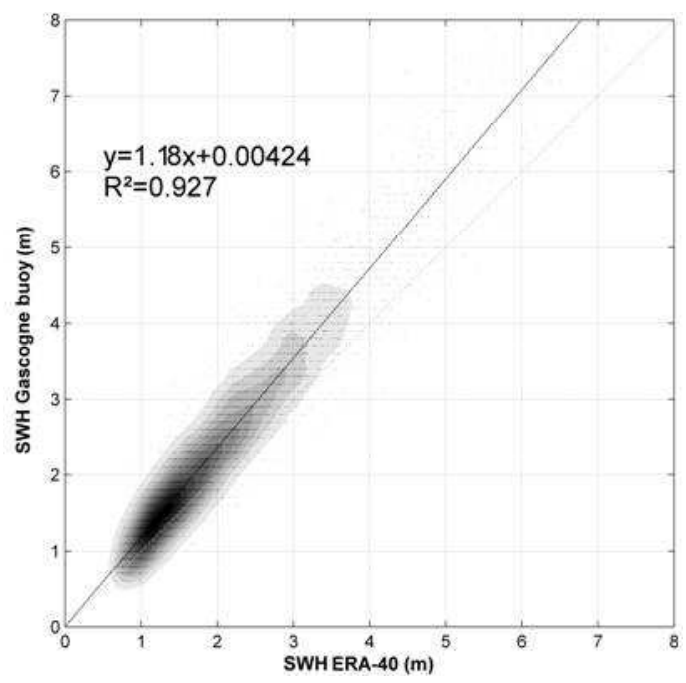

Figure 2. A regression curve of ERA-40 modelled SWH versus the Gascogne buoy observations during the overlapping time period from July 1998 to August 2002. Gray scaling indicates the dataset density. 

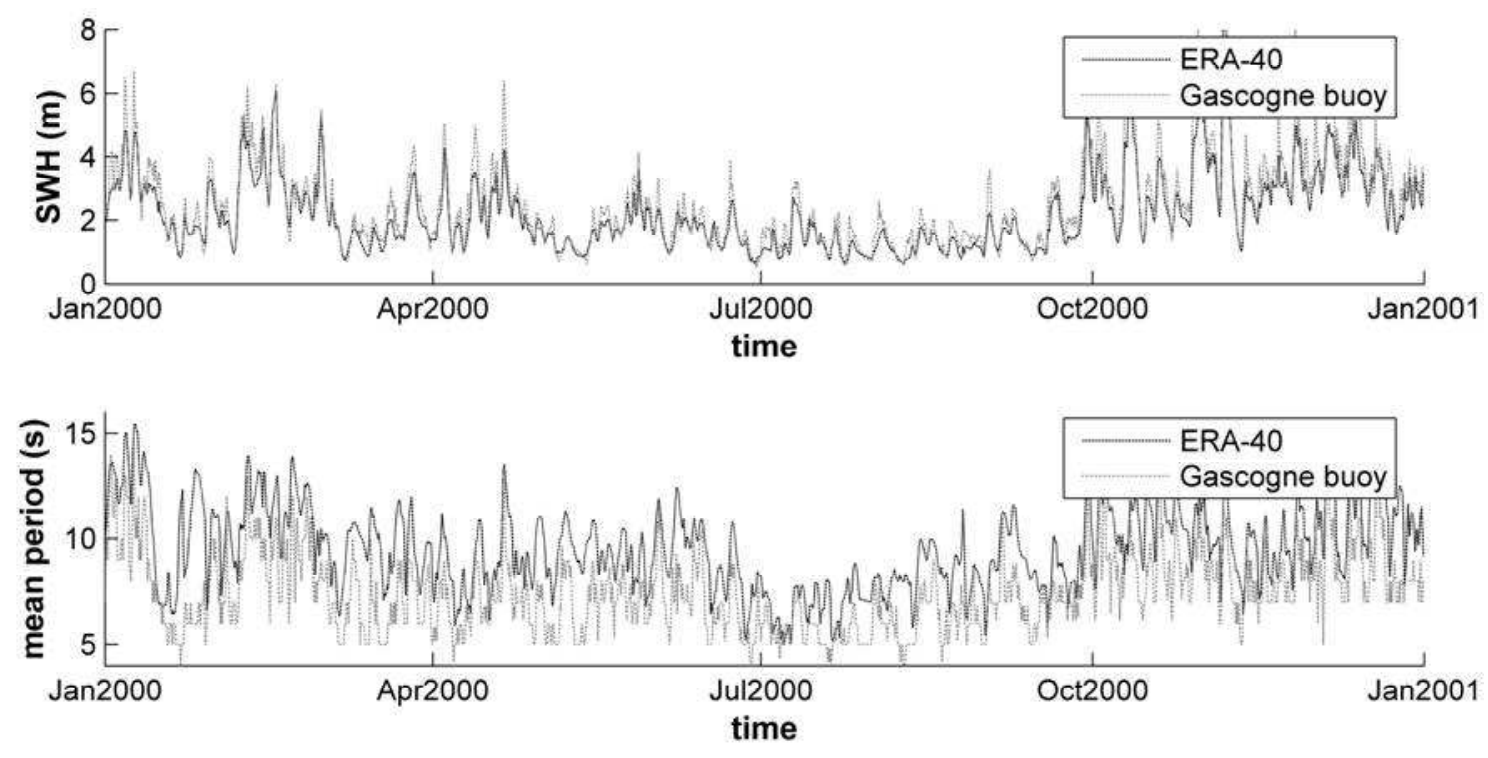

Figure 3. Comparison of SWH and T modelled in ERA-40 versus the Gascogne buoy observations over a subset of the overlapping period from January 2000 to January 2001.

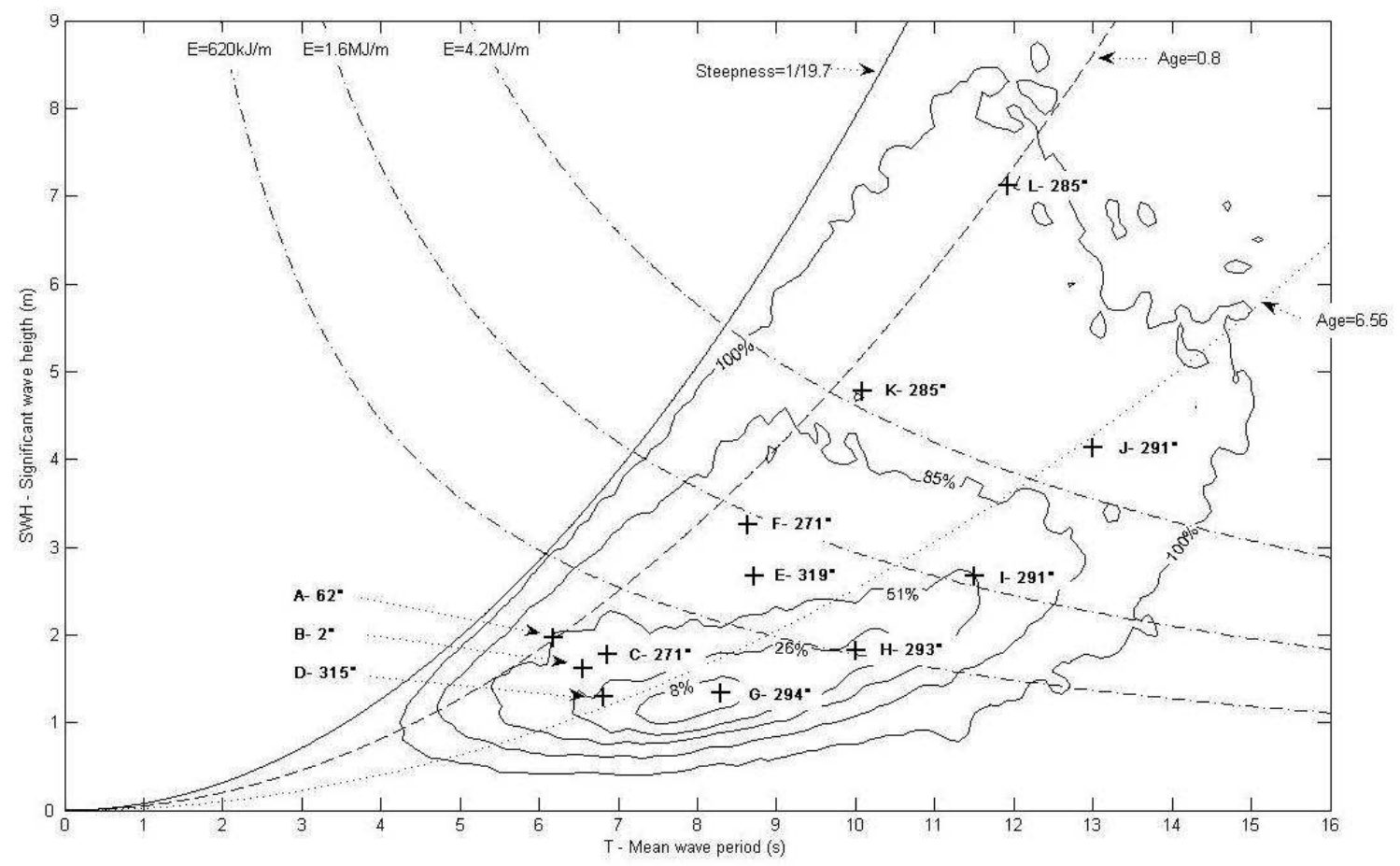

Figure 4: Bivariate diagram plotting $\mathrm{T}$ against $\mathrm{SWH}$. Contour lines are plotted around $100 \%, 85 \%, 51 \%, 26 \%$ and $8 \%$ of the dataset. Barycentres obtained by classification 
are designated according to Table 4 together with their mean direction. The curve of constant steepness $1 / 19.7$ corresponds to fully developed seas. Waves located above the curve of a constant age of 0.8 correspond to wind seas. The curve corresponding to a constant age of 6.56 corresponds to the mean $(50 \%$ of the waves are lying below this curve). The iso-energy fluxes are also plotted for the $50^{\text {th }}, 75^{\text {th }}$ and $90^{\text {th }}$ percentiles, corresponding respectively to values of $620 \mathrm{~kJ} / \mathrm{m}, 1.6 \mathrm{MJ} / \mathrm{m}, 4.2 \mathrm{MJ} / \mathrm{m}$.

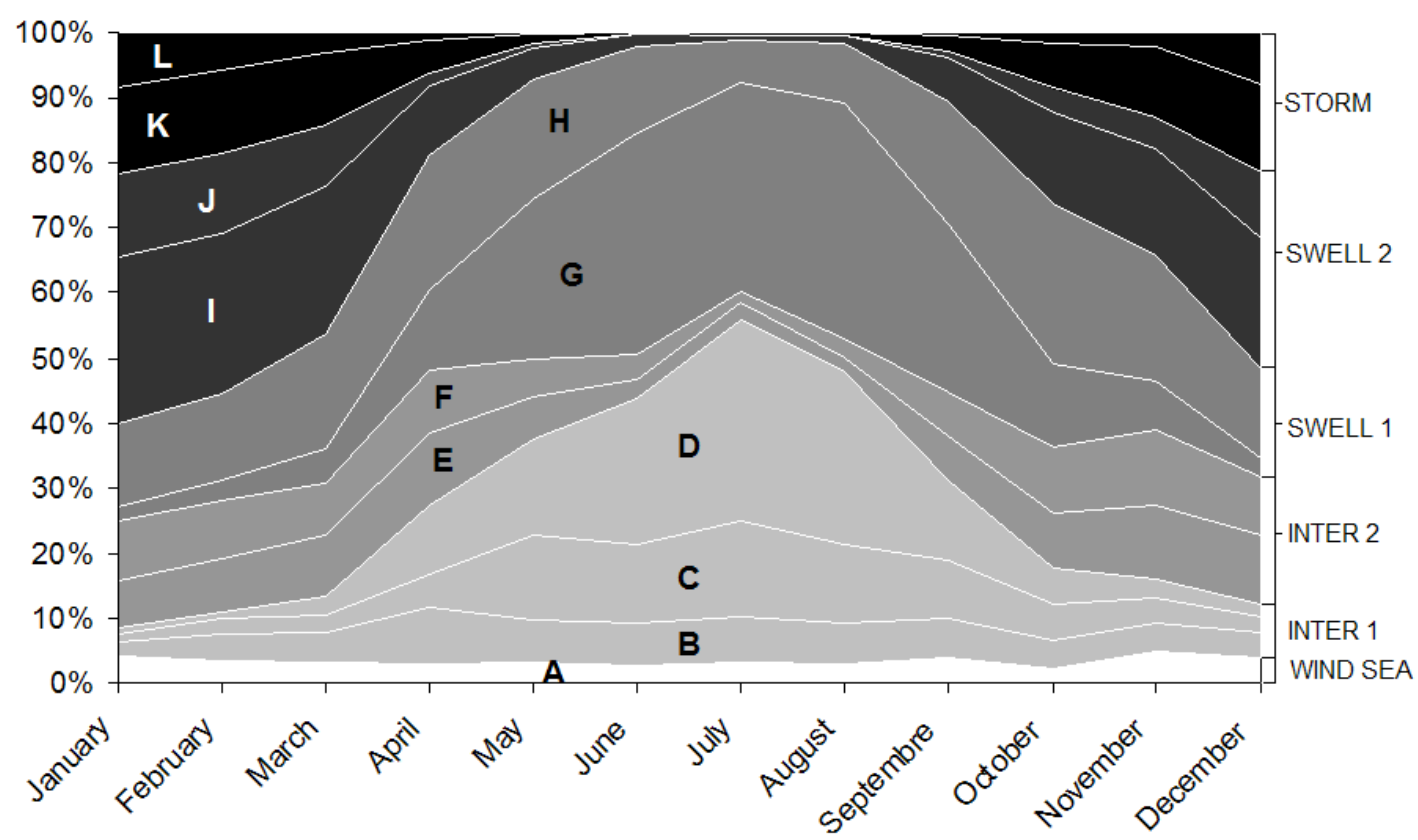

Figure 5. Seasonal occurrence of the 12 classes for the period 1958-2001 
NAO index mean vs SWELL2 + STORM annomaly

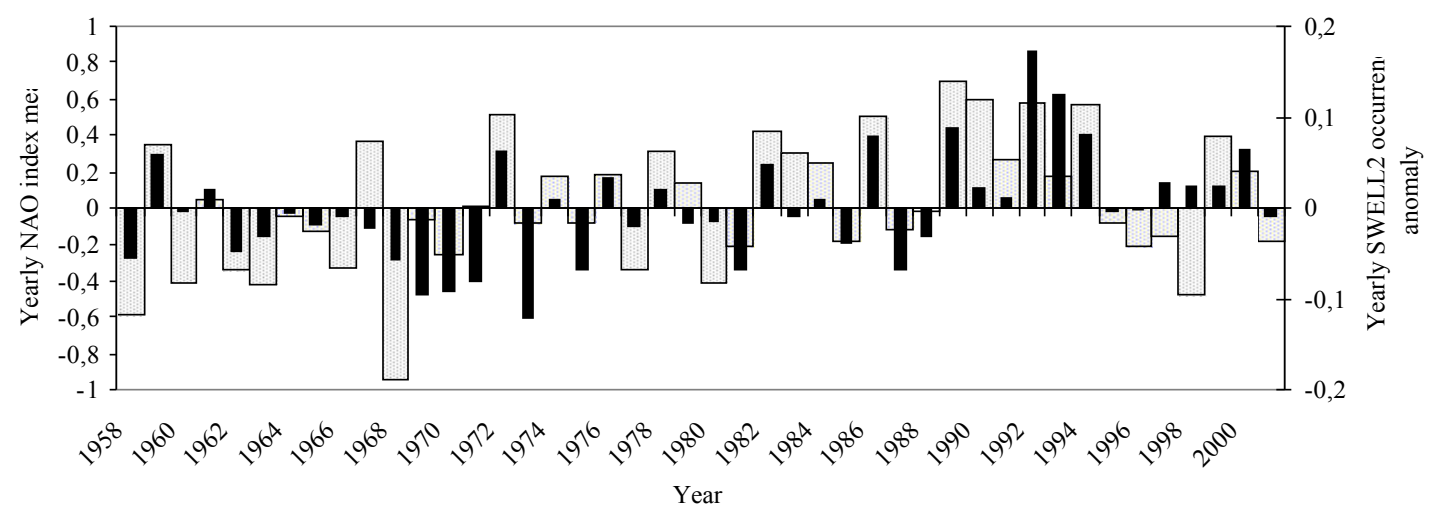

Figure 6. Time series of mean annual NAO index (histogram) compared to annual occurrence anomalies of SWELL $2+$ STORM waves (thin bars) 


\section{Tables}

Table 1. Sea state datasets referred to in this study

\begin{tabular}{llll}
\hline \hline Code & Name & Acquisition & Reference \\
\hline LIMA & Lima Ocean Weather Ship & 1975 to 1988 & Bacon \& Carter 1991 \\
SEV & Seven Stones Light Vessel & 1962 to 1986 & Bacon \& Carter 1991 \\
BISC & Biscarosse buoy & 1980 to 2000 (discontinuous) & Dupuis, 2006 \\
GASC & Gascogne buoy & 1998 to present & \\
ERA-40 & ERA-40 reanaly sis Gascogne point & 1957 to 2001 (Model) & Caires \& Sterl 2001 \\
\hline
\end{tabular}

Table 2. Teleconnection patterns considered in this article and changes in storminess in the North Atlantic associate $d$ with a positive inde $x$ value of one standard deviation (See Figure 1) (Seierstad et al. 2007).

Teleconnection patterns quote d here are those define d by Barnston and Livezey (1987)

\begin{tabular}{|c|c|c|}
\hline $\begin{array}{l}\text { Short- } \\
\text { ening }\end{array}$ & Teleconnection pattern & $\begin{array}{l}\text { Associated storminess anomaly in northern Atlantic for a positive phase of } \\
\text { the index (Seierstad et al. 2007) }\end{array}$ \\
\hline $\mathrm{NAO}$ & Northern Atlantic Oscillation & $\begin{array}{l}\text { Increased storminess in the south Greenland and Iceland regions. } \\
\text { Decreased storminess off Spain }\end{array}$ \\
\hline EA & East Atlantic Pattern & Increased storminess in the Central Eastern Atlantic \\
\hline EA/WR & $\begin{array}{l}\text { East Atlantic / Western Russia } \\
\text { pattern (also called Eurasian } \\
\text { pattern type 2) }\end{array}$ & $\begin{array}{l}\text { Decreased storminess in the Bay of Biscay. Increased storminess in the } \\
\text { central part of Northern Atlantic }\end{array}$ \\
\hline $\mathrm{EP} / \mathrm{NP}$ & $\begin{array}{l}\text { East pacific / north pacific } \\
\text { pattern }\end{array}$ & Increased storminess in the Bay of Biscay \\
\hline WP & West pacific pattern & $\begin{array}{l}\text { West pacific pattern not creating significant storminess changes over } \\
\text { Northern Atlantic after Seierstad et al. (2007) }\end{array}$ \\
\hline
\end{tabular}

Table 3. Comparison between the Gascogne buoy data set and the ERA40 dataset. The scatte $r$ index is de fined as the standard deviation of the error normalised by the observation mean [following Bidlot et al. (2001)].

\begin{tabular}{cccc|cccc}
\hline & \multicolumn{3}{c}{} & \multicolumn{4}{c}{ Mean period (T) } \\
\hline Bias & RMS error & $\mathrm{R}^{2}$ & Scatter index & Bias & RMS error & $\mathrm{R}^{2}$ & Scatter index \\
$-40 \mathrm{~cm}$ & $60 \mathrm{~cm}$ & 0.927 & $17 \%$ & $2 \mathrm{~s}$ & $2.5 \mathrm{~s}$ & 0.75 & $17 \%$ \\
\hline
\end{tabular}


Table 4. Results of the wave classification in the Bay of Biscay

\begin{tabular}{|c|c|c|c|c|c|}
\hline \multirow{2}{*}{$\begin{array}{l}\text { Wave } \\
\text { class } \\
\text { name }\end{array}$} & \multirow[t]{2}{*}{ Description (Type, incident direction, saisonnality) } & \multicolumn{3}{|c|}{ Class barycentre } & \multirow{2}{*}{$\begin{array}{l}\text { Mean yearly } \\
\text { occurrence } \\
(\%)\end{array}$} \\
\hline & & Hs (m) & $\mathrm{T}(\mathrm{s})$ & $\mathrm{D}\left({ }^{\circ}\right)$ & \\
\hline A & WIND SEA / ENE / annual & $2 \mathrm{~m}$ & $6.2 \mathrm{~s}$ & $62^{\circ}$ & $3.4 \%$ \\
\hline $\mathrm{B}$ & INTER 1 / N / annual & $1.6 \mathrm{~m}$ & $6.6 \mathrm{~s}$ & $2^{\circ}$ & $5.4 \%$ \\
\hline $\mathrm{C}$ & INTER 1 / W / mostly spring, summer, autumn & $1.8 \mathrm{~m}$ & $6.9 \mathrm{~s}$ & $271^{\circ}$ & $7.1 \%$ \\
\hline $\mathrm{D}$ & INT ER 1 / NW / mostly spring, summer, autumn & $1.3 \mathrm{~m}$ & $6.8 \mathrm{~s}$ & $315^{\circ}$ & $11.1 \%$ \\
\hline $\mathrm{E}$ & INT ER 2 / NW / mostly spring, autumn, winter & $2.7 \mathrm{~m}$ & $8.7 \mathrm{~s}$ & $319^{\circ}$ & $7.2 \%$ \\
\hline $\mathrm{F}$ & INTER 2 / W / mostly spring, autumn, winter & $3.3 \mathrm{~m}$ & $8.6 \mathrm{~s}$ & $271^{\circ}$ & $7.3 \%$ \\
\hline G & SWELL 1 / WNW / mostly spring, summer, autumn & $1.3 \mathrm{~m}$ & $8.3 \mathrm{~s}$ & $294^{\circ}$ & $16.6 \%$ \\
\hline $\mathrm{H}$ & SWELL 1 / WNW / annual & $1.8 \mathrm{~m}$ & $10.0 \mathrm{~s}$ & $293^{\circ}$ & $15.7 \%$ \\
\hline I & SWELL 2 / WNW / mostly spring, autumn, winter & $2.7 \mathrm{~m}$ & $11.5 \mathrm{~s}$ & $291^{\circ}$ & $12.4 \%$ \\
\hline $\mathrm{J}$ & SWELL 2 / WNW / spring, autumn, winter & $4.1 \mathrm{~m}$ & $13.0 \mathrm{~s}$ & $291^{\circ}$ & $4.7 \%$ \\
\hline $\mathrm{K}$ & STORM / WNW / spring, autumn, winter & $4.8 \mathrm{~m}$ & $10.1 \mathrm{~s}$ & $285^{\circ}$ & $6.5 \%$ \\
\hline $\mathrm{L}$ & STORM / WNW / spring, autumn, winter & $7.1 \mathrm{~m}$ & $11.9 \mathrm{~s}$ & $285^{\circ}$ & $2.6 \%$ \\
\hline
\end{tabular}

Table 5: Trends of annual mean significant wave heights from 1970 to 2001 . Data: ERA40 $\left(45^{\circ} \mathrm{N} / 5^{\circ} \mathrm{W}\right.$ node) corrected by linear regression. Bold coefficients show the significant tre nds at the 0.05 confidence level.

\begin{tabular}{lccc}
\hline \hline Dataset & $\begin{array}{c}\text { Linear trend of } \\
\text { wave group } \\
\text { annual ratio }\end{array}$ & SWH linear trend & $\begin{array}{c}\text { Mean occurrence } \\
\text { over 1970 - 2001 }\end{array}$ \\
\hline all & Not applicable & $\mathbf{+ 0 . 0 0 8} \mathbf{~ m} /$ year & Not applicable \\
WIND SEA & 0.0003 year $^{-1}$ & $0.001 \mathrm{~m} /$ year & $3.2 \%$ \\
INTER 1 & $\mathbf{- 0 . 0 0 3 9 \text { year } ^ { - 1 }}$ & $\mathbf{0 . 0 0 5 m} /$ year & $23.3 \%$ \\
INTER 2 & 0.0003 year $^{-1}$ & 0.0008 m/year & $14.2 \%$ \\
STORM & 0.0003 year $^{-1}$ & 0.0001 m/year & $9.1 \%$ \\
SWELL 1 & 0.0002 year $^{-1}$ & 0.002 m/year & $32.3 \%$ \\
SWELL 2 & $\mathbf{0 . 0 0 2 9}$ year $^{-1}$ & 0.002 m/year & $17.9 \%$ \\
\hline
\end{tabular}


Table 6. Correlation coefficients $R$ be tween relative annual frequency of occurre nce for each wave group and relevant annual te leconnection pattern indexes (civil year). Bold coefficie nts show the significant corre lations at the 0.05 confidence level.

\begin{tabular}{lcccc}
\hline & NAO & EA & EA/WR & EP/NP \\
\hline WIND SEA & $\mathbf{- 0 . 3 1}$ & -0.24 & -0.17 & 0.10 \\
INTER 1 & -0.25 & $\mathbf{0 . 3 4}$ & -0.15 & 0.08 \\
INTER 2 & $\mathbf{- 0 . 3 9}$ & 0.28 & 0.03 & 0.21 \\
SWELL 1 & -0.20 & 0.06 & 0.10 & -0.23 \\
SWELL 2 & $\mathbf{0 . 5 3}$ & 0.17 & 0.24 & 0.27 \\
STORM & $\mathbf{0 . 4 3}$ & 0.15 & 0.20 & 0.28 \\
\hline INTER & $\mathbf{- 0 . 4 4}$ & -0.19 & 0.17 & 0.20 \\
SWELL 2 + STORM & $\mathbf{0 . 6 3}$ & 0.20 & 0.14 & $\mathbf{0 . 3 4}$ \\
\hline
\end{tabular}

Table 7. Corre lation coefficients $R$ be tween relative winter (December, January, February) frequency of occurence and relevant annual teleconnection patte rns indexes (civil year) from 1957 to 2001 . Bold coefficie nts show the significant correlations at the 0.05 confidence level.

\begin{tabular}{lcccc}
\hline & NAO & EA & EA/WR & EP/NP \\
\hline SWELL 1 & -0.21 & -0.18 & 0.20 & 0.04 \\
SWELL 2 & $\mathbf{0 . 4 0}$ & 0.18 & $\mathbf{0 . 5 8}$ & 0.23 \\
STORM & 0.25 & $\mathbf{0 . 5 2}$ & $\mathbf{- 0 . 5 7}$ & 0.15 \\
\hline WIND SEA + INTER & $\mathbf{- 0 . 5 4}$ & $\mathbf{- 0 . 5 4}$ & -0.26 & $\mathbf{- 0 . 3 8}$ \\
SWELL 2 + STORM & $\mathbf{0 . 5 8}$ & $\mathbf{0 . 5 6}$ & 0.16 & $\mathbf{0 . 3 3}$ \\
\hline
\end{tabular}

